\title{
Eye disease in newly diagnosed leprosy patients in eastern Nepal
}

\author{
W. J. LUBBERS, ${ }^{*}$ A. SCHIPPER, \\ MARGREET HOGEWEG $\dagger \ddagger$ \& $\&$ \\ R. DE SOLDENHOFF $\S$
}

$\S N S L / E a s t e r n$ Leprosy Control Project, PO Box 134, Biratnagar, Nepal; $\dagger$ Department of Ophthalmology, State University of Leiden, The Netherlands; $\ddagger$ Netherlands Leprosy Relief Organization NSL, Wibautstraat 135, 1097 DN Amsterdam, The Netherlands; and *State University of Groningen, The Netherlands

\section{Accepted for publication 28 March 1994}

Summary To determine the magnitude of eye lesions in newly diagnosed leprosy patients we examined their eyes.

The Eastern Leprosy Control Project was supported by The Netherlands Leprosy Relief Association; we used the regional clinic in Biratnagar and 5 mobile clinics in surrounding districts as our survey area.

All patients who presented at the clinics over 10 weeks, diagnosed as having untreated leprosy were included.

Of the 260 examined patients $97(37 \cdot 3 \%, 95 \%$ confidence interval $28 \cdot 3-$ $40 \cdot 3 \%)$ had an eye lesion; $12 / 260$ patients $(4 \cdot 6 \%, 95 \%$ confidence interval $2 \cdot 0$ $7 \cdot 2 \%$ ) had sight-threatening lesions (lagophthalmos, iris involvement, corneal anaesthesia), directly related to leprosy; $46(17 \cdot 7 \%)$ patients were diagnosed as having some degree of cataract; 2 patients were aphakic; 3 patients $(1 \cdot 2 \%)$ were blind according to the WHO definition.

In this series of new and untreated leprosy patients many eye lesions found are not relevant or leprosy related. There were 9 new patients with lagophthalmos, some too longstanding to treat with steroids. We found 3 patients with iris involvement. The figures we found for eye lesions, sight-threatening lesions and blindness are low when compared to other studies. The number of patients with any grade of cataract is high. The average total of leprosy patients who were blind can be compared with the average total who are blind in the general population.

\ Correspondence: Department of Ophthalmology, Leiden University, PO Box 9600, 2300 RC Leiden, The Netherlands. 


\section{Introduction}

Involvement of the eye in leprosy is well known and several prevalence studies have been carried out among different populations, but mainly within leprosy institutions. ${ }^{1-9}$ As far as we know no studies have been done on the eye problems which exist at the moment the patient is diagnosed. This assessment of the starting condition is important in order to study the effect of MDT treatment on the development of leprosy related eye complications. ${ }^{8,10}$ The most important leprosy-related sight-threatening lesions are lagophthalmos and iris involvement. Lagophthalmos is caused by the involvement of the facial nerve in the disease process, either by direct invasion of the nerve by Mycobacterium leprae or due to a Type 1 leprosy reaction (reversal reaction) in the nerve. The complications of lagophthalmos which cause blindness are damage to the exposed cornea with consequent ulcers and opacities. Corneal anaesthesia occurs either in combination with lagophthalmos or as a result of invasion and atrophy of the corneal nerves. Iris involvement also arises from different mechanisms; there is either direct invasion of the anterior eye and secondary atrophy or reaction to an antigen load that causes iridocyclitis in Type 2 leprosy reaction (ENL). Blindness may result subsequently from a miotic pupil, secondary cataract and secondary glaucoma.

This study has been done in eastern Nepal. The setting is described elsewhere. ${ }^{11}$

\section{Patients and methods}

Between September and November 1992 (10 weeks) we examined all new patients who presented at the clinics and were diagnosed as having leprosy.

After recording a registration number, age, sex, type of leprosy, duration of disease, district and presenting symptom the eyes were examined.

Visual acuity (VA) was tested with the Snellens E-chart and if necessary with finger counting. Pinhole examination was done when VA $<9 / 12$. Facial patches were drawn.

Eye examination was carried out in a semidark area. We closely examined lids, brows, conjunctiva, sclera and the lacrimal system with focal illumination. We looked for lagophthalmos by measuring the gap at mild and strong closure and by testing the strength of the orbicularis oculi muscle.

The cornea was checked with a lighted loupe (magnification $7 \times$ ) for opacities and pannus; the iris for signs of iridocyclitis, iris atrophy or iris pearls. Pupil size was measured with a transparent measure and shape and reaction to light noted down. The corneal sensitivity was tested with cottonwool. The eye was then stained with fluorescein to look for punctate staining. All patients' pupils were dilated with tropicamide and cataract grading was done using direct ophthalmoscopy. ${ }^{12}$ Any eye history was noted down. All data were recorded on a proforma adapted from that proposed by ffytche. ${ }^{13}$

\section{Results}

POPULATION

We saw 260 newly-diagnosed leprosy patients. The mean age was $34 \cdot 5$ years. There were 88 females and 170 males. In all, $41 \%$ of the patients suffered from the TT or BT type of 
Table 1. Eye-problems in 260 new leprosy patients

\begin{tabular}{|c|c|c|}
\hline $\begin{array}{l}\text { Eye brows } \\
\text { Madarosis } \\
\text { lateral } \\
\text { total }\end{array}$ & $\left.\begin{array}{r}20^{*} \\
6^{*}\end{array}\right\}$ & $19 \mathrm{MB}, 9 \mathrm{~PB}$ \\
\hline $\begin{array}{l}\text { Eye lid } \\
\text { Lagophthalmos (1 eye) } \\
\text { Nodules } \\
\text { Chalazion } \\
\text { Ptosis } \\
\text { Blepharospasm } \\
\text { Blepharochalasis } \\
\text { Blepharitis } \\
\text { Trichiasis }\end{array}$ & $\begin{array}{l}9^{*} \\
1^{*} \\
3 \\
1 \\
1 \\
1 \\
1 \\
1 *\end{array}$ & $\begin{array}{l}3 \mathrm{BL}, 4 \mathrm{BT}+, 2 \mathrm{PNL} \\
\mathrm{LL} \\
\mathrm{BT}+\text {, TT } \\
\text { BT } \\
\text { PNL } \\
\text { LL } \\
\text { BT+ } \\
\text { BT+ }\end{array}$ \\
\hline $\begin{array}{l}\text { Conjunctiva and sclera } \\
\text { Conjunctivitis } \\
\text { Scleral leproma } \\
\text { Pterygium } \\
1 \text { eye } \\
2 \text { eyes }\end{array}$ & $\left.\begin{array}{r}21 \\
6\end{array}\right\}$ & $\begin{array}{l}\mathrm{BT}+ \\
\mathrm{LL}, \mathrm{BL}\end{array}$ \\
\hline $\begin{array}{l}\text { Cornea } \\
\text { Corneal opacity } \\
\text { Corneal sensitivity reduced }\end{array}$ & $\begin{array}{r}11 \\
1\end{array}$ & $\begin{array}{l}\text { 4MB, 7PB } \\
\text { PNL }\end{array}$ \\
\hline $\begin{array}{l}\text { Iris } \\
\text { Iridocyclitis (acute) } \\
\text { Irispearls } \\
\text { Synechiae } \\
\text { ant (traumatical) } \\
\text { post } \\
\text { Irreg. pupil shape } \\
\text { Different pupil size L \& R }\end{array}$ & $\begin{array}{l}1^{*} \\
1^{*} \\
1 \\
1 * \\
1 \\
5\end{array}$ & $\begin{array}{l}\text { BL } \\
\text { LL } \\
\text { TT } \\
\text { BL } \\
\text { BT+ } \\
1 \mathrm{MB}, 4 \mathrm{~PB}\end{array}$ \\
\hline $\begin{array}{l}\text { Lens } \\
\text { Cataract } \\
1 \text { eye } \\
2 \text { eyes } \\
\text { Aphakia }\end{array}$ & $\begin{array}{r}7 \\
38 \\
2\end{array}$ & \\
\hline $\begin{array}{l}\text { Total } \\
\text { Sight threatening }\end{array}$ & $\begin{array}{r}144(\mathrm{i} \\
13(\mathrm{i}\end{array}$ & $\begin{array}{l}\text { n } 97 \text { patients: } 37 \cdot 3 \% \text { ) } \\
\text { n } 13 \text { patients: } 5 \cdot 0 \% \text { ) }\end{array}$ \\
\hline
\end{tabular}

${ }^{*}$ Leprosy related.

leprosy which was treated with a 6-month multidrug regimen, and $59 \%$ suffered from the $\mathrm{BT}+, \mathrm{BB}, \mathrm{BL}, \mathrm{LL}$ and PNL type of leprosy and were treated with a 24-month regimen. $\mathrm{BT}+$ is defined in Nepal as having patches and/or nerves involved in at least 3 body areas. ${ }^{14}$ The mean duration of disease, according to the patients, was 22.8 months. The population is described more extensively elsewhere. ${ }^{11}$

\section{EYE LESIONS}

In 97 patients $(37 \cdot 7 \%)$ we found 1 or more of the eye problems listed below in Table 1. Visual acuity of all 520 eyes is given in Table 2. Aphakic eyes were tested with spherical 
Table 2. Visual acuity in 520 eyes/best eye in 260 patients

\begin{tabular}{|c|c|c|}
\hline & Eyes & Patients \\
\hline $6 / 18$ or better (normal) & $471(90 \cdot 6)^{*}$ & $244(93 \cdot 8)$ \\
\hline $6 / 24-6 / 36$ (impaired) & $22(4 \cdot 2)$ & $6(2 \cdot 3)$ \\
\hline $6 / 60-3 / 60$ (severely impaired) & $19(3 \cdot 7)$ & $7(2 \cdot 7)$ \\
\hline Less than $3 / 60$ (blind) & $8(1 \cdot 6)$ & $3(1 \cdot 2)$ \\
\hline Total & 520 & 260 \\
\hline
\end{tabular}

* Numbers in parentheses are percentages.

+10 correction. Sight-threatening lesions (lagophthalmos, iris involvement and corneal insensitivity) were found in 12 patients $(4 \cdot 6 \%)$. Some of the eye-problems of Table 1 will now be described more extensively.

\section{LAGOPHTHALMOS $(n=9)$}

Lagophthalmos was defined as a consistent gap on mild closure with muscle weakness of the orbicularis oculi. In all, 3 patients had multibacillary leprosy (BL) and the other 6 had paucibacillary leprosy (PNL and BT+). Only 1 of the lagophthalmos patients had reduced vision ( $6 / 18$ both eyes), but this was caused by cataract. The other 8 patients had good vision (6/6). There were no other eye lesions apart from a slight conjunctivitis in 1 eye, and 3 patients had a severe lagophthalmos with a gap on strong closure. The duration of lagophthalmos according to the patient was less than 2 months in 4 patients, more than 2 years in 2 patients and 3 patients did not know they had lagophthalmos. These results are summarized in Table 3 .

\section{IRIS INVOLVEMENT $(n=3)$}

Of the 3 patients, 1 (male, 35 years, BB, duration of disease 96 months) had a slight pain in the left eye with pericorneal redness, a small pupil with sluggish reaction to light and only slight dilation with tropicamide. Vision was $6 / 6$ in both eyes but was subjectively decreased in the affected eye, another (male, 30 years, BL, duration of disease 18 months) had old posterior synechiae in both eyes but had no signs of active iridocyclitis (VA both eyes 6/36), and patient 3 (male, 35 years, BL, duration of disease 48 months) had an atrophic iris of the left eye (VA left 6/12, right 6/18), but no active signs of iridocyclitis.

CORNEAL HYPAESTHESIA $(n=1)$

There was 1 patient (PNL) with unilateral reduced sensitivity which was probably not leprosy related (accident).

CORNEAL OPACITY $(n=11)$

Of the 11,1 patient had a severe leprous keratitis in both eyes in the upper outer quadrant with a vision of $6 / 18$ in both eyes, and the rest had opacities which were not leprosy related; most of them were only small nebular lesions. 
Table 3. Lagophthalmos in 9 new leprosy patients

\begin{tabular}{|c|c|c|c|c|c|c|c|}
\hline No. & Age & Type & $\begin{array}{l}\text { Dur. } \\
\text { lepr. } \\
(\mathrm{m})\end{array}$ & $\begin{array}{l}\text { Dur. } \\
\text { lag. } \\
\text { (m) }\end{array}$ & $\begin{array}{c}\text { Gap } \\
\text { mild } \\
\text { closure } \\
(\mathrm{mm})\end{array}$ & $\begin{array}{c}\text { Gap } \\
\text { strong } \\
\text { closure } \\
(\mathrm{mm})\end{array}$ & Remarks \\
\hline 1 & 26 & BL & 2 & 1 & 2 & 0 & \\
\hline 2 & 36 & $\mathrm{BL}$ & 2 & 2 & 2 & 0 & \\
\hline 3 & 60 & $\mathrm{BL}$ & 12 & $?$ & 2 & 0 & in reaction, start steroids \\
\hline 4 & 8 & $\mathrm{BT}+$ & 84 & 42 & 5 & 3 & patch \\
\hline 5 & 20 & $\mathrm{BT}+$ & 60 & $?$ & 2 & 0 & patch in reaction, start st. \\
\hline 6 & 35 & $\mathrm{BT}+$ & 2 & 2 & 5 & 2 & patch, start steroids \\
\hline 7 & 55 & $\mathrm{BT}+$ & 12 & $?$ & 1 & 0 & \\
\hline 8 & 19 & PNL & 48 & 24 & 5 & 3 & patch \\
\hline 9 & 28 & PNL & 2 & 2 & 2 & 0 & start steroids \\
\hline
\end{tabular}

All patients were male, only unilateral lagophthalmos.

dur. lepr.: duration of leprosy in months.

dur. lag.: duration of lagophthalmos in months.

\section{CATARACT/APHAKIA $(n=47)$}

Of the 47 patients, 38 had cataracts in both eyes and 7 in 1 eye. The severity of the cataracts in these 83 eyes is given in Table 4 .

We did not find a correlation between cataract and classification in this series of new untreated and relatively young patients. The percentage of patients with cataracts (more than $1 / 2$ ) was $7 \cdot 0 \%$ in the paucibacillary group and $5.0 \%$ in the multibacillary group. There was 1 patient with 1 aphakic eye and 1 with 2 aphakic eyes after cataract extraction.

MADAROSIS $(n=26)$

In 6 patients there was a complete madarosis and in 20 patients a lateral madarosis. In 5 of the 26 cases lateral madarosis was found in paucibacillary patients (probably as a normal variant).

Table 4. Cataract grading (520 eyes)

\begin{tabular}{lrr}
\hline Grade & No. & $\%$ \\
\hline 0 no cataract & 434 & $(83 \cdot 5)$ \\
1 spot & 26 & $(5 \cdot 0)$ \\
$2<1 / 2$ & 25 & $(4 \cdot 8)$ \\
$3>1 / 2$ & 25 & $(1 \cdot 8)$ \\
4 complete & 8 & $(0 \cdot 6)$ \\
5 aphakia & 3 & $(100 \cdot 0)$ \\
\hline Total & 520 & \\
\hline
\end{tabular}


BLINDNESS $(n=3)$

According to the WHO definition blindness is defined as a VA in the better eye of less than $3 / 60$. There were 3 blind patients found. There were 2 more patients with 1 blind eye. All were caused by cataract.

\section{Discussion}

In his article about methodology Courtright pointed out the major shortcomings in methodology of surveys on ocular complications in leprosy. ${ }^{4}$ Although some of these were also unavoidable in our survey (clinic based, sequentially sampled population) we tried to avoid the others as much as possible.

Eye lesions of some kind were found in $37 \%$ of the newly diagnosed patients $(95 \%$ confidence interval $28 \cdot 3-40 \cdot 3 \%$ ). This is much lower than the figure found in Nepalese leprosy institutions: $69 \cdot 8 \%, 74 \cdot 2 \%$ and $57 \cdot 3 \%{ }^{5-7}$ Courtright mentioned in his critical survey 'ocular complications' in $1-91 \%(!) .{ }^{4}$

Leprosy related 'eye problems' including madarosis but excluding cataract were found in $15.4 \%$ (95\% confidence interval $10 \cdot 9-19 \cdot 9 \%)$ of the patients. Without madarosis the figure is $6.9 \%$ (95\% confidence interval $3 \cdot 8-10 \cdot 0 \%)$. ffytche found 'significant ocular involvement' (excluding cataract) in $21.9 \%$ in a series of surveys.' In South India $24 \%$ of eye lesions were diagnosed as being due to leprosy in outpatients in a big institution. ${ }^{1}$ It is difficult to compare these figures but it seems that leprosyrelated eye problems are less in new patients than in patients under treatment or after treatment. In the present study sight-threatening lesions (lagophthalmos, iris involvement and corneal anaesthesia) were found in $4 \cdot 6 \%$ (95\% confidence interval $2 \cdot 0-7 \cdot 2 \%)$ compared with $24 \cdot 3 \%$ by ffytche and $8 \cdot 22 \%$ in South India. ${ }^{1,2}$ In institutions this figure is also high but cannot be compared.

We found cataracts in $17 \cdot 7 \%(95 \%$ confidence interval $12 \cdot 0-23 \cdot 4 \%)$; cataracts with an absent red light reflex and a poor vision of less than $6 / 60$ were found in $2 \cdot 7 \%$. ffytche found cataracts (defined as either aphakia or visible lens opacities or an absent red reflex with VA $<6 / 36$ ) in $17 \cdot 2 \% .^{9}$ In leprosaria in Nepal $8 \cdot 2 \%$ of the eyes were found to have a VA of $<6 / 60$ as a result of cataract. The average age was $59 \cdot 8$ years. Cataract in that series was seen more commonly among lepromatous patients, as a result of iridocyclitis. ${ }^{15}$ In Nepal there is cataract in $2 \cdot 8 \%$ of the general population; in the terai $4 \cdot 17 \%{ }^{16}$

We found blindness in 3 patients, i.e. $1 \cdot 2 \%$ (95\% confidence interval $0-2 \cdot 6 \%)$. ffytche found blindness in $5 \%$ or $7 \%$ (VA $<6 / 60$ ) (depending on the definition of blindness) $;{ }^{9}$ in South India there was blindness in $0.8 \%$ and in Nepalese institutions in $6 \cdot 0 \%$ and $2 \cdot 4 \% .^{1,5,7}$ In another study in a Nepalese institution $12 \cdot 7 \%$ of the eyes were blind (VA < 6/60). ${ }^{6}$ According to an epidemiological survey on blindness in Nepal the overall figure for Nepal is $0.84 \%$ and for the Eastern and Central terai regions more than $1 \%{ }^{16}$ If we take the age distribution into account we find in the prevalence per age group mentioned in the survey in Nepal a predicted prevalence of $2.9 \%$; corrected for age the number we found $(1 \cdot 2 \%)$ is low. Courtright mentioned in his survey $0-50 \%(!) .{ }^{4}$ In our study all lagophthalmos patients and all patients with iris involvement were male. We have no explanation for this finding.

The mean age of patients is not mentioned in many studies but most probably our patients are younger than patients in resettlement villages or leprosaria. 
Ideally populations should be compared using age, sex, type of disease, systemic treatment and duration of disease. Unfortunately this is often not possible.

\section{Conclusions}

The first conclusion of this study is that eye problems in newly diagnosed patients do exist. Lagophthalmos and iridocyclitis are potentially treatable and should be detected early.

The second conclusion is that the figure for blindness in newly diagnosed patients is relatively low $(1 \cdot 2 \%)$ and can be compared with the figure in the general population, although this must be corrected for age and sex, and the numbers are small. This means that eye complications in new patients have not yet damaged the vision severely.

The figure we found for eye lesions is much lower than the figure found in other studies, mainly because the research carried out up to now was not done in newly diagnosed patients. The patients studied in previous research were older, had suffered from leprosy longer, and there was a big selection bias because the most disabled patients tend to end up in institutions. The figure we found for cataract is relatively high. This is probably because we used a sensitive method. Because of the lack of correlation with classification the cataract in this relatively young population does not seem to be leprosy related.

Our results stress the importance of a good eye examination both in new cases and in cases under treatment. ${ }^{17}$ The examination we carried out can be done without using any high technology equipment like a slit lamp, although some patients with early iris changes may be missed. Competent field workers can and should perform this examination almost everywhere (perhaps with the exception of the tropicamide).

Iridocyclitis should be treated with local corticosteroids and atropine, and any lagophthalmos which had developed or progressed during the previous 6 months should be treated with oral steroids. ${ }^{18}$

Detection of poor eye sight or blindness in leprosy is of extra importance because the patient may already be disabled by sensory loss.

Careful documentation of any eye complications at the start of treatment is necessary as it forms the baseline for further assessment, and also enables the effect of MDT to be seen on the incidence of new eye complications. It would be interesting to examine the same group of patients after treatment and after, for example 5 years.

\section{References}

1 Soshamma G, Suryawanshi N. Eye lesions in leprosy. Lepr Rev, 1989; 60: 33-8.

2 ffytche, TJ. Residual sight threatening lesions in leprosy patients completing multidrug therapy and sulphone monotherapy. Lepr Rev, 1991; 62: 35-43.

3 ffytche, TJ. The American Peace Corps Survey of the ocular complications of leprosy in South Korea: an evaluation and appraisal. Lepr Rev, 1984; 55: 239-46.

4 Courtright PD. Defining the magnitude of ocular complications from leprosy, problems of methodology. Int J Lepr, 1988; 56: 566-73

5 Brandt F, Malla OK. Ocular findings in leprous patients. A report of a survey in Malunga/Nepal. Albrecht von Graefes Arch Klin Ophthalmol, 1981; 217: 27-34.

6 Malla OK, Brandt F, Anten JGF. Ocular findings in leprosy patients in an institution in Nepal(Khokana). Br J Ophthalmol, 1981; 65: 226-30. 
${ }^{7}$ Brandt F, Kist P, Wos J. Augenbefunde bei Lepra, Ergebnisse einer Studie im Green-Pastures LeprosyHospital Pokhara/Nepal. Klin Mbl Augenheilk, 1981; 178: 55-8 (German).

${ }^{8}$ Rajan MA. Eye in multidrug therapy. Ind J Lepr, 1990; 62: 33-8.

9 ffytche T. Blindness in leprosy - a forgotten complication. Australian and New Zealand Journal of Ophthalmology, 1989; 17: 257-60.

10 Editorial. Ocular complications in leprosy. Lancet, 1992; 340: 642-3.

11 Schipper A, Lubbers WJ, Hogeweg M, Soldenhoff R de. Disabilities of hands, feet and eyes in newly diagnosed leprosy patients in Eastern Nepal. Lepr Rev, 1994; 65: 239-47.

12 Mehra V, Minassian DC. A rapid method of grading cataract in epidemiological studies and eye surveys. $\mathrm{Br}$ J Ophth, 1988; 72: 801-3.

13 ffytche TJ. A computer form to aid in the collection of data on the ocular complications of leprosy. Lepr Rev, 1983; 54: 271-81

14 van Brakel WH, de Soldenhoff R, McDougall AC. The allocation of leprosy patients into paucibacillary and multibacillary groups for multidrug therapy, taking into account the number of body areas affected by skin, or skin and nerve lesions. Lepr Rev, 1992; 63: 231-46.

15 Brandt F, Kampile A, Malla OK, Pokhrel RP, Wos J. Blindness from cataract formation in leprosy. Dev Ophthal, 1983; 7: 1-12.

16 Brilliant LB, Pokhrel RP, Grasset NC et al. Epidemiology of blindness in Nepal. Bull WHO, 1985; 63(2): 375-86.

17 Courtright PD, Lewallen S. Considerations in the integration of eye care into leprosy care services. Lepr Rev, 1992; 63: 73-7.

18 Kiran KU, Hogeweg M, Suneetha S. Treatment of recent facial nerve damage with lagophthalmos, using a semistandardized steroid regimen. Lepr Rev, 1991; 62: 150-4. 